\section{BMJ Paediatrics Open}

\title{
Setting up and running a paediatric emergency department in a hospital in Malawi: 15 years on
}

Elizabeth M Molyneux, ${ }^{1}$ Josephine Langton, ${ }^{1}$ Jenala Njiram'madzi, ${ }^{1}$ Ann M Robertson ${ }^{2}$

To cite: Molyneux EM, Langton J, Njiram'madzi J, et al. Setting up and running a paediatric emergency department in a hospital in Malawi: 15 years on. BMJ Paediatrics Open 2017;1:e000014. doi:10.1136/ bmjpo-2017-000014

- Prepublication history for this paper is available online. To view these files please visit the journal online (http://dx.doi.org/ 10.1136/bmjpo-2017-000014).

Received 21 March 2017 Revised 7 April 2017 Accepted 10 April 2017
CrossMark

${ }^{1}$ Paediatric Department, College of Medicine, Queen Elizabeth Central Hospital, Blantyre, Malawi

${ }^{2}$ Emergency Department, Macclesfield Hospital, Macclesfield, UK

Correspondence to Professor Elizabeth M Molyneux; emmolyneux@gmail.com

\section{ABSTRACT}

Paediatric emergency care is not recognised as a specialty in many countries in Africa but is being practised increasingly. Setting up a paediatric emergency care unit takes time and often involves trial and error. Here we describe the start of the paediatric emergency department in Blantyre, Malawi, a low-income country and how it has continued to evolve over 15 years, in the hope that our experience will inform and assist others who are already developing their own emergency unit or wishing to do so.

\section{INTRODUCTION}

Paediatric emergency medicine, though a relatively young discipline is recognised as a specialty in an increasing number of countries and hospitals. The first paediatric resuscitation conference was held in 1983 under the auspices of the American Heart Association, ${ }^{1}$ and in the UK it became a paediatric subspecialty in the mid-1980s. Emergency medicine is practised in 50 countries $^{2}$ worldwide but very few countries in Africa recognise paediatric emergency as a specialty per se. In a survey of African emergency care, Obermeyer et al were able to identify 192 facilities, just over half $(\mathrm{n}=107)$ were part of an academic health unit, only $11(6 \%)$ were in rural areas and $36(19 \%)$ were separate children's departments. ${ }^{3}$ In most African district hospitals, emergency medicine, outpatients and immunisation clinics are held simultaneously in one place and run by the same staff. Triage is minimal and the service is often left to the least trained and least supervised health workers. All of this is well known, but what is newsworthy is the increasing number of paediatricians and front-line health workers who are creating emergency care services in their own hospitals and how paediatric emergency care is gradually establishing itself on the continent as a recognised and rewarding specialty.
What is already known about the subject this topic?

Paediatric emergency departments contribute to timely, effective care of sick children.

- Training and team work are essential to delivering a good service.

- Good use of space and adequate equipment lead to a smooth flow of patients through the emergency department.

\section{What this study hopes to add?}

We have found little in the literature on experience of running such a unit in a poorly resourced setting and none on how to sustain it and make it grow.

- We explain our experience in undertaking such a task and our experience in building the unit up over 15 years, to try to help others embarking on a similar venture.

We present our experience in establishing a paediatric emergency department in the hope that it will encourage others to think about any such need in their own health unit and help them to develop what is best for their particular setting.

\section{Background}

The Queen Elizabeth Central Hospital (QECH) opened in 1964 with 300 beds; it is now an 1100-bedded tertiary care, general, government hospital in Blantyre, Malawi. It serves the southern region of the country but is also the district hospital for the local population. Since 1991 the QECH is the main teaching hospital for the medical school. The paediatric department admits approximately 26000 children, up to 15 years of age, annually. A further 65000 are treated without admission. 


\section{As it was}

Before 2001 almost all children were admitted through what was called the Under Fives Clinic (UFC). This was a large square-roofed area that had been converted from a covered parking lot. There were four rooms at its periphery, one was used for supplementary feeding of
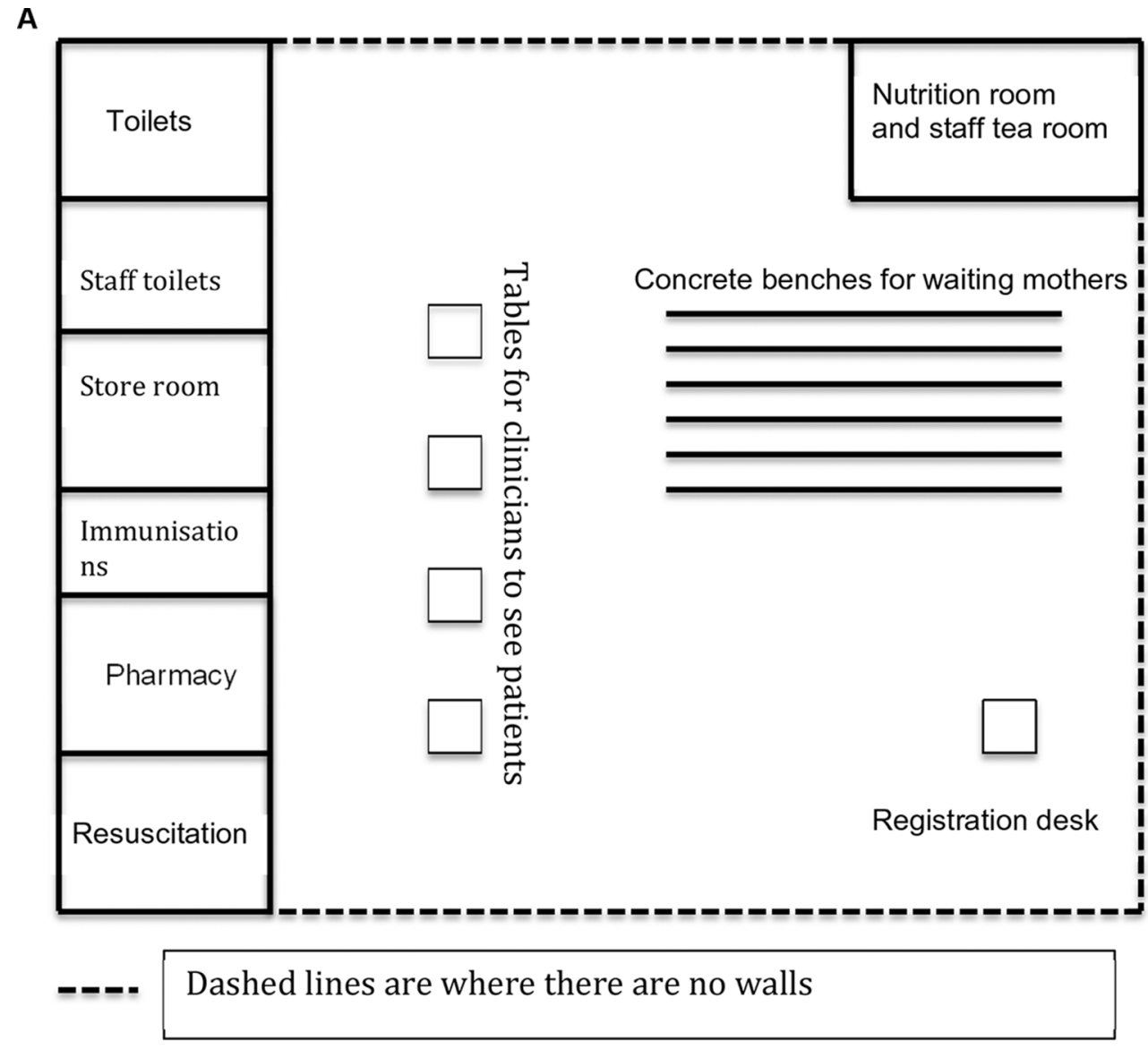

B

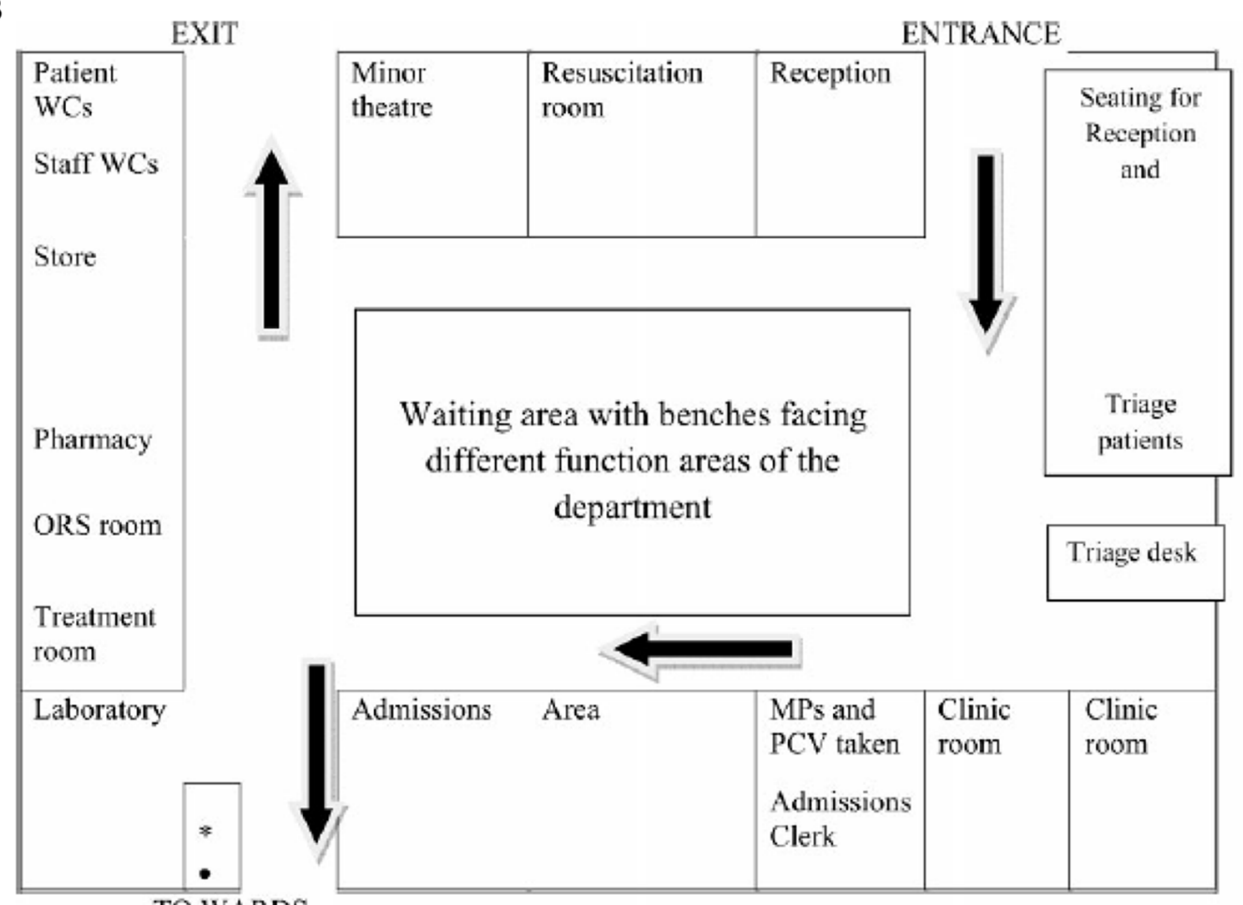

TO WARDS

Figure 1 (A) Old floor plan of the Under Fives Clinic (pre-2001). (B) Present floor plan of the emergency department. ORS, oral rehydration solution. MP, malaria parasites; PCV, blood tested for malaria parasites and packed cell volume; WC, toilet. 


\section{Queen Elizabeth Central Hospital Paediatric Admission Sheet}

Date______ Time_____ NAME

\begin{tabular}{|c|c|c|c|c|}
\hline \multicolumn{3}{|r|}{ AGE } & \multicolumn{2}{|c|}{ HIV R/NR/E/U } \\
\hline HISTORY & & & & Details Please \\
\hline Fever & $\mathrm{Y} / \mathrm{N}$ & How long for... & & \\
\hline Convulsions & $\mathrm{Y} / \mathrm{N}$ & Description... & & \\
\hline Diarrhoea & $\mathrm{Y} / \mathrm{N}$ & How long for... & & \\
\hline Vomiting & $\mathrm{Y} / \mathrm{N}$ & How long for... & & \\
\hline Cough & $\mathrm{Y} / \mathrm{N}$ & How long for... & & \\
\hline Difficulty Breathing & $\mathrm{Y} / \mathrm{N}$ & How long for... & & \\
\hline Rash & $\mathrm{Y} / \mathrm{N}$ & How long for... & & \\
\hline Pallor & $\mathrm{Y} / \mathrm{N}$ & How long for... & & \\
\hline Jaundice & $\mathrm{Y} / \mathrm{N}$ & How long for... & & \\
\hline Oedema & $\mathrm{Y} / \mathrm{N}$ & How long for... & Allergies & $\mathrm{Y} / \mathrm{N}$; comment.. \\
\hline Problems Urinating & $\mathrm{Y} / \mathrm{N}$ & How long for... & Transfusions & $\mathrm{Y} / \mathrm{N}$; dates... \\
\hline $\begin{array}{l}\text { Problems Feeding } \\
\text { other... }\end{array}$ & $\mathrm{Y} / \mathrm{N}$ & How long for... & $\begin{array}{l}\text { Vacc Complete } \\
\text { Recent Meds }\end{array}$ & $\begin{array}{l}\mathrm{Y} / \mathrm{N} \text {; comment.. } \\
\mathrm{Y} / \mathrm{N} \text {; list... }\end{array}$ \\
\hline
\end{tabular}

BACKGROUND

Known Diagnoses/Previous Admissions/Birth History...

HIV

\begin{tabular}{|c|c|c|c|}
\hline \multirow[t]{3}{*}{ Child } & $\mathrm{R} / \mathrm{NR} / \mathrm{E} / \mathrm{U}$ & Mother & $\mathrm{R} / \mathrm{NR} / \mathrm{U}$ \\
\hline & RDT/PCR/verbal & & RDT/PCR/verbal \\
\hline & Date... & & Date... \\
\hline COT & Y/N; Started... & сот & $\mathbf{Y} / \mathbf{N}$; Started... \\
\hline $\mathbf{R}^{\prime}$ & Y/N; Started... & ART & $\mathbf{Y} / \mathrm{N}$; Started... \\
\hline PMTC & $\mathbf{Y} / \mathbf{N}$ & PMTCT & $\mathrm{Y} / \mathrm{N}$ \\
\hline
\end{tabular}

$\begin{array}{llll}\text { ART } & \text { Y/N; Started... } & \text { ART } & \text { Y/N; Started... } \\ \text { PMTCT } & \text { Y/N } & \text { PMTCT } & \text { Y/N }\end{array}$

\begin{tabular}{|c|c|c|c|c|}
\hline FAMILY HISTORY & Details Please & Mother well & $\mathrm{Y} / \mathrm{N}$ & \\
\hline TB contact & $\mathrm{Y} / \mathrm{N}$ & Father well & $\mathrm{Y} / \mathrm{N}$ & \\
\hline Epilepsy & $\mathrm{Y} / \mathrm{N}$ & Parents separated & $\mathrm{Y} / \mathrm{N}$ & When... \\
\hline Diabetes & $\mathrm{Y} / \mathrm{N}$ & $\begin{array}{l}\text { Number of siblings } \\
\text { Siblings well }\end{array}$ & $\mathrm{Y} / \mathrm{N}$ & $\begin{array}{l}\text { Alive... Dead... } \\
\text { Ages... }\end{array}$ \\
\hline
\end{tabular}

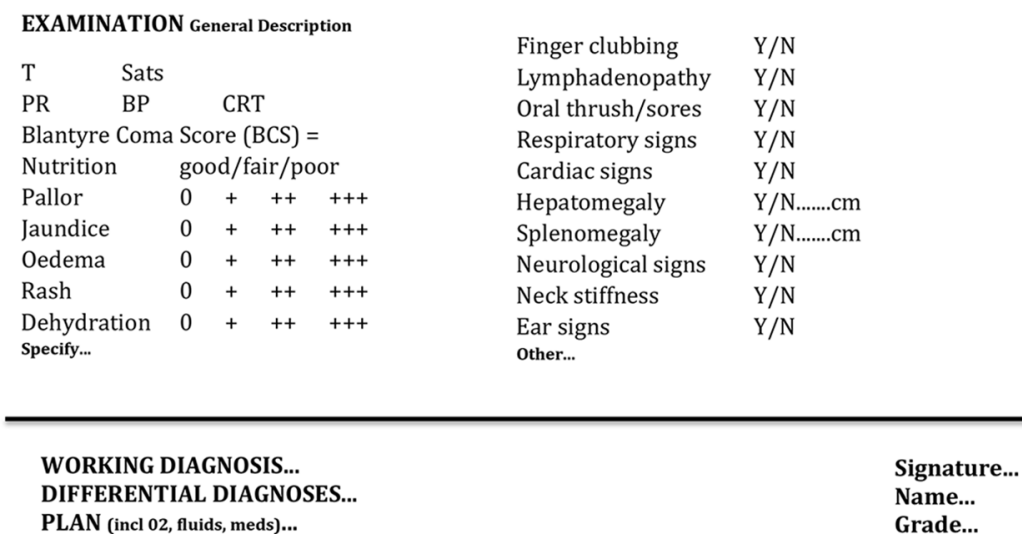

Figure 2a Admission sheet and Critical Care Pathway for inpatients in the Queen Elizabeth Central Hospital.R/NR/E/U, Reactive; Non Reactive, Exposed/Unexposed. RDT/PCR, Rapid Diagnostic Test/Polymerase chain reaction; COT, cotrimoxazole; ART, antiretroviral therapy,;PMTCT, Prevention of Mother to Child Transmission; BP, blood pressure, CRT, capillary refill time; PR, pulse rate; CSF, cerebral spinal fluid; RR, resiratory rate; DOB, date of birth; QECH, Queen Elizabeth Cnetral Hospital, CCP, critical care pathway.

malnourished children three times a week and doubled up as the staff tea room, another was an immunisation room, one was a consulting room and the fourth was for resuscitation of children who were clearly in need of immediate attention, such as those with seizures (figure 1a). However most investigations and treatments were carried out on the ward and patients were taken in groups down to the ward to wait until the doctors had finished their ward rounds and could formally admit the children.

In the UFC, children were seen on a first come, first serve basis by medical assistants who sat at desks in the central section of the building. Women queued in lines in front of a desk with their children waiting to be seen; there was no privacy, numbers were very high and the medical assistants were unsupervised. UFC 


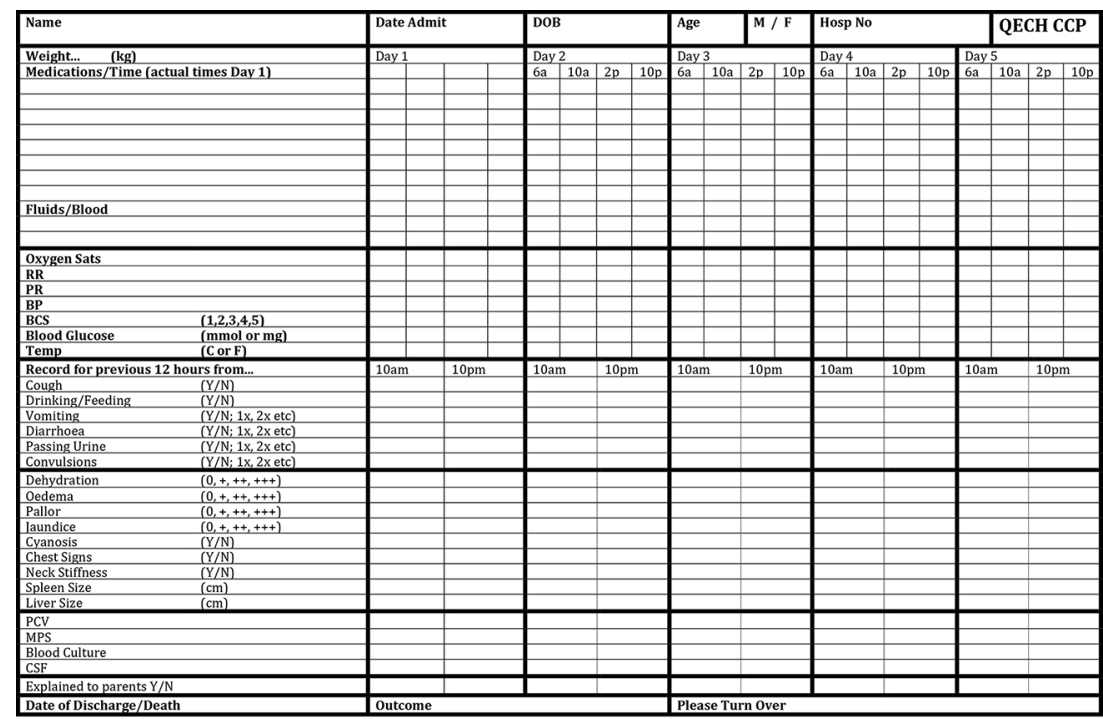

Figure 2b Queen Elizabeth Central Hospital Admission and Monitoring Sheet.

did have a small pharmacy with some basic drugs or mothers were sent to the main hospital pharmacy to get medicines to take home.

Clearly there was room for improvement but we were anxious lest unsupportable changes led to the total collapse of a very fragile system.

\section{First things first-structure and equipment}

The layout of the old UFC was poor, but the footprint was adequate, and a complete rethink was needed to allow for good patient flow through the department. Rebuilding costs money and the bigger donors are not usually interested in funding capital costs, especially at a tertiary care unit. It took persistence and time (7 years) before we finally found funding from the European Union (EU) to redesign and rebuild the old UFC into an emergency unit and add a separate outpatient section and a short-stay ward (figure 1a old UFC, figure $1 \mathrm{~b}$, new floor design). These opened in 2001. Having attracted funds for the infrastructure made it easier to source additional charitable funds to build the short stay ward and hire five nurses. Some equipment was needed which was in part from the EU and from a Dutch charity that had acquired useful items from an unused 1950s' military field hospital.

\section{Training and supervision}

Emergency medicine was a new concept, triage was unknown and so all the staff needed training. Colleagues from the UK had helped validate the WHO course called Emergency Triage Assessment and Treatment, ${ }^{4}$ based on the Advanced Paediatric Life Support course, ${ }^{5}$ and stayed to teach it to the nurses and clinical officers. One of us (AMR), a trained emergency physician, stayed for 18 months and helped embed the teaching into the routine health system. She supervised the unit staff, the on-call junior doctors and all the resuscitations as well as managing the available resources. First-line investigations were done in the emergency unit and treatments, including blood transfusions, given so that there would be no delay on the wards. As much as possible all children were stabilised before being taken to a ward.

\section{Patient flow}

Experienced staff who worked in the department were consulted about patient flow. This helped to avoid problems and lack of ownership at a later date.

Triaged patients were allocated to different areas depending on need with the very sick being managed straight away by a clinician or senior nurse.

A small research laboratory carried out thick blood films for malaria and a haematocrit on every child.

Minor injuries and fractures were seen twice daily in the department by the orthopaedic team.

Patients who were not well enough to be sent straight home but who would probably have improved by the end of the day (especially from malaria) were kept in the short-stay ward for 4-6hours; if still not well enough for discharge they were admitted. This facility, which had not been part of the capital spend, significantly reduced admission numbers helping to free up time for the ward staff to manage the sickest patients.

Patients with gastroenteritis were given oral fluids in the oral rehydration solution (ORS) room and reviewed after several hours.

Outpatients were now seen in a separate building attached to the emergency department and during the rebuilding of the department, the immunisations were moved back to local health centres.

Importantly the nurses were able to triage and to send non-urgent cases to their local health centre which they had bypassed to come to the hospital.

Embedding any change in practice takes time but can be achieved with ongoing supervision.

\section{Documentation}

Admission sheets and critical care pathways were introduced to the department in 1997 and these are very helpful when admitting large numbers of children. 


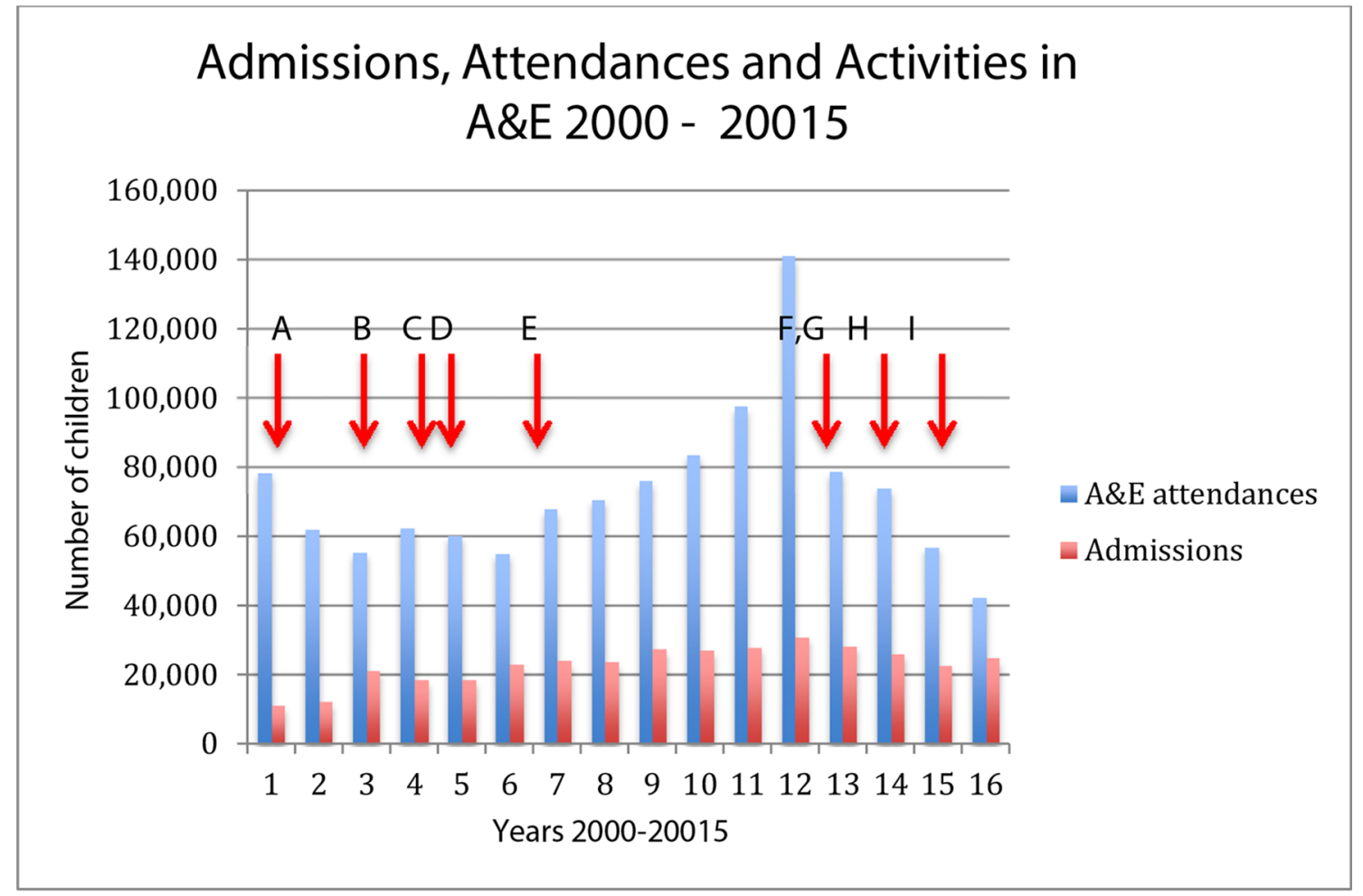

\section{A 2001 Accident and Emergency Department opened and ETAT introduced B 2003 National Blood Transfusion Service commences C 2004 registrar stationed in A\&E \\ D 2005 child abuse: post exposure prophylaxis, treatment and forensic examinations carried out in side room of $A \& E$ \\ E 2007 antimalarial first line treatment changes to lumefantrine - artemesinin \\ F 2012 One Stop Centre opens \\ G 2012 gate clinic opens \\ H 2013 HIV councillor based in A\&E \\ I 2014 A\&E stays open 24 hours}

Figure 3 Admissions, attendances and activities in the emergency department. ETAT, emergency triage assessment and treatment.

They are economical in space (when paper is scarce), have many prompts to remind staff of what data need to be collected and bring together on one sheet some of the important nursing observations, treatment and results. They can be an excellent source for audits ${ }^{67}$ (figure 2a,b).

\section{Care of abused children}

From 2001 onwards improvement and refinements in the care of abused children have been made, one step at a time.

In 2004 a pro forma for the medical examination of abused children was created. A consultant and a registrar examined a child together and made notes that could stand up in court to forensic scrutiny. An HIV rapid test was done at the time of the examination and postexposure prophylaxis offered when medically appropriate. Retesting was offered after a 3-month period in case of seroconversion. ${ }^{8}$ A social worker was assigned to the department to care for these children, but he was often drawn away for other duties in the social work department. As a consequence there were difficulties in interagency communication and cooperation. In 2012 this changed when a specific centre for abused children and women, the One Stop Centre, was opened. The centre is staffed by a paediatric nurse, a clinical officer, social workers, counsellors and a trained police officer. Interagency cooperation has improved significantly. Since then the medical staff have continued to examine and provide medical reports and the number of prosecutions and convictions has increased from 3\% to $70 \% .^{9}$ The trained volunteer counsellors offer a highly regarded, long-term service to the victims.

\section{Blood transfusion}

In 2003 a national blood transfusion service was started. This enabled the hospital blood bank to provide blood more quickly to the emergency department (ED), which in turn was able to immediately resuscitate profoundly anaemic children in a closely supervised environment. 
Table 1 Number of yearly emergency department attendances, malaria cases, admissions and inpatient deaths from 2000 to $2016, \mathrm{n}(\%)$

\begin{tabular}{rrlll}
\hline Year & AED & Admissions & $\begin{array}{l}\text { Inpatient } \\
\text { deaths }\end{array}$ & $\begin{array}{l}\text { Malaria } \\
\text { cases in } \\
\text { A\&E }\end{array}$ \\
\hline 2000 & 78519 & 11124 & $1540(13.8 \%)$ & ------ \\
\hline 2001 & 62069 & 12291 & $1269(10 \%)$ & 7392 \\
\hline 2002 & 55482 & 21336 & $1325(6.2 \%)$ & 9251 \\
\hline 2003 & 62513 & 18430 & $1201(6.5 \%)$ & 7217 \\
\hline 2004 & 60294 & 18618 & $1202(6.4 \%)$ & 8572 \\
\hline 2005 & 55062 & 22947 & $1973(8.5 \%)$ & 4591 \\
\hline 2006 & 67948 & 24074 & $1609(6.7 \%)$ & 4062 \\
\hline 2007 & 70639 & 23794 & $1750(7.3 \%)$ & 5969 \\
\hline 2008 & 76145 & 27481 & $1822(6.6 \%)$ & 5903 \\
\hline 2009 & 83702 & 27145 & $1793(6.2 \%)$ & 5374 \\
\hline 2010 & 97607 & 27968 & $1740(6.9 \%)$ & 5132 \\
\hline 2011 & 141080 & 30888 & $1591(6.9 \%)$ & 6330 \\
\hline 2012 & 78873 & 28333 & $1419(5.0 \%)$ & 3521 \\
\hline 2013 & 74075 & 26066 & $1518(5.8 \%)$ & 2209 \\
\hline 2014 & 56913 & 22831 & $1331(5.8 \%)$ & 2594 \\
\hline 2015 & 42494 & 24759 & $1373(5.5 \%)$ & 2254 \\
\hline 2016 & 60316 & 21587 & $1184(5.5 \%)$ & 2241 \\
\hline
\end{tabular}

AED, Accident and Emergency Department.

This was a great improvement from the previous scenario when blood was donated by a relative leading to long delays in transfusing a child on the ward.

\section{Progress}

When the number of paediatric trainees increased we were able to assign one registrar to the emergency department. This person spent much time in resuscitation and supervised the interns who were admitting patients. A senior opinion often meant that a child could be sent safely home on treatment rather than being admitted unnecessarily.

HIV counsellors were assigned to the emergency department to try to ensure that all untested children who attend the department are tested with precounselling and postcounselling.

A major drawback had been that there were only sufficient staff to cover the day and at night all emergencies had to be seen in an admission/emergency room near the wards. Often this room was staffed by locum nurses who were unused to emergency routines and came late on shifts.

In 2013 we were finally able to keep the Accident and Emergency (A\&E) department open for 24 hours. This was done by judicious rearrangement of staff duties and an increase of two nurses to the nursing establishment of five. An increase in interns meant that one be could be stationed in A\&E overnight reducing delay in accessing medical help.
Figure 3 shows the new activities or changes that took place in the department in relation to annual attendances and admissions from 2000 to 2016. Over time there has been a significant change in perception of the department by hospital staff. Few nurses used to be allocated by the ministry to work in the ED. Now it has become a place where staff want to work. Training has moved from courses requiring per diem to no-cost, inhouse, continuous professional development.

Malawian nurses interested in paediatrics have undertaken a master's course in paediatrics first organised by the Red Cross Children's Hospital in Cape Town, South Africa; but now fully run by the Malawi Kamuzu School of Nursing. ${ }^{10}$ One of the graduates was matron of the A\&E department but has since moved on. The present incumbent is going to Australia to undertake training in paediatric emergency nursing.

When the pharmacy withdrew staffing for the small pharmacy in A\&E it was taken over and run by one of the nurses.

Several audits and small, implementation studies have been carried out such as

the ability to do triage; ${ }^{11}$ the overall results from resuscitations ${ }^{12}$ the effect of HIV infection on outcome of patients admitted to the resuscitation room,${ }^{13}$ the outcome from severe gastroenteritis was reviewed and the management of trauma examined.

\section{Where are we now?}

The department is open 24 hours a day and is staffed by trained health workers. There is a full-time consultant in the department and one, often two, registrars assigned to work there. Two interns are assigned to the department every day and the on-call intern stays overnight. There is a matron and there are seven nurses who cover day and night shifts. One clinical officer sees many of the routine attendees, helped by one or two clinical officers who are attached to research projects but help in the department when not caught up in other duties.

HIV councillors opportunistically test any untested children attending the department.

The short stay ward admits children who will probably be sent home after a time of observation. These children are reviewed in the late afternoon to make the decisions as to whether to admit or discharge home. Only about $10 \%$ of children in short stay are admitted.

Children with gastroenteritis requiring oral rehydration are supervised in an ORS room and reviewed later in the day to determine the need for admission or not.

The One Stop Centre is a stand-alone unit but the children to be seen there are channelled through the emergency unit.

Outpatient clinics are in a close but separate building and the emergency unit nurses and clerks staff the clinics.

An orthopaedic clinical officer comes twice a day to manage all the trauma cases-mainly fractures-referred to him. 


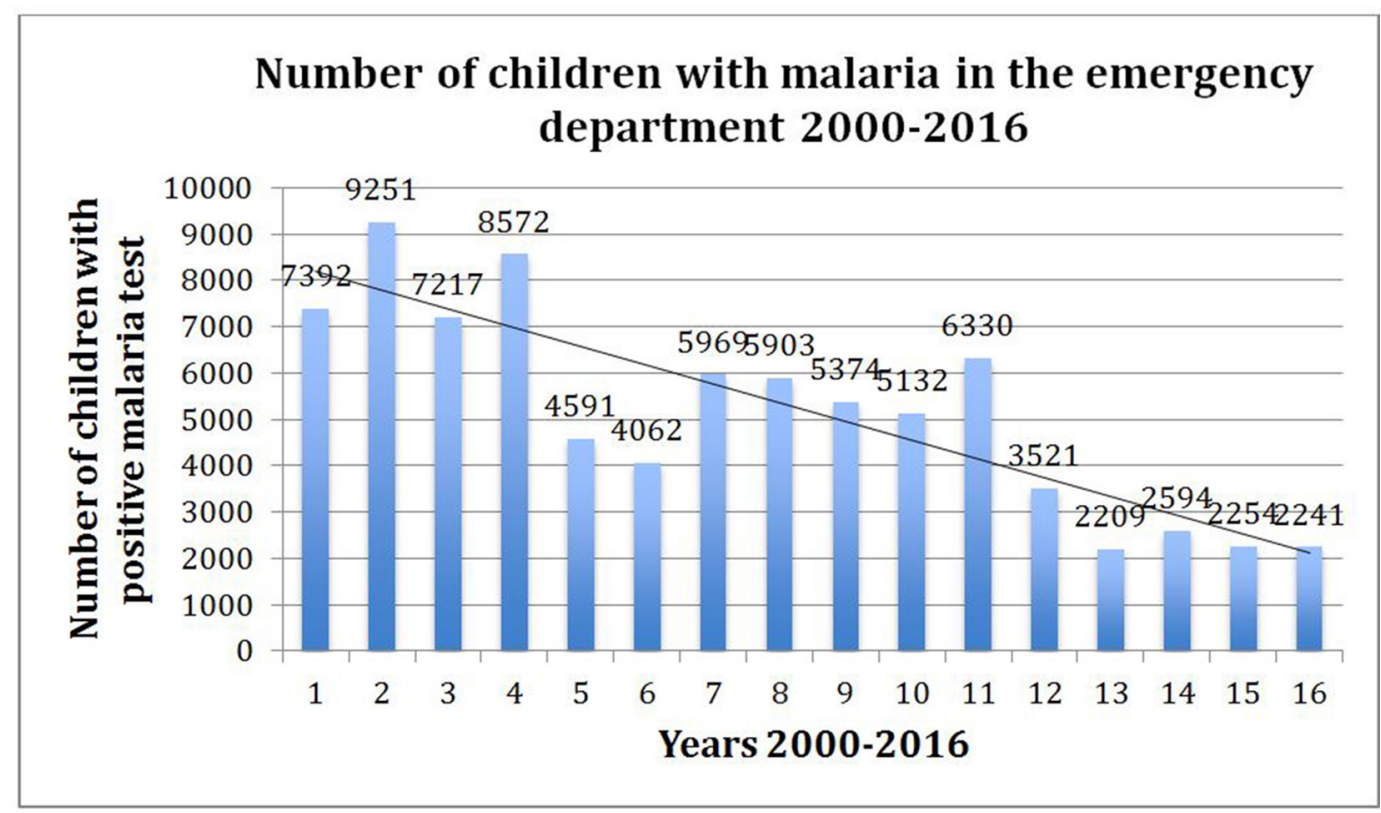

Figure 4 The number of children with malaria attending the emergency department, 2000-2016.

A primary care unit called the Gateway Clinic has been opened near to the hospital so that many of the more minor cases are seen there rather than coming to the emergency unit.

The number of children attending with malaria has decreased, this may be in part because simple cases are being seen and treated in the Primary Care Unit and because of a more effective first line therapy for malaria (table 1, figure 4).

\section{The future}

The number and proportion of admissions has increased steadily over the years despite a decrease in overall attendees at the emergency unit. The outcomes of inpatients have improved year on year. (table 1). Regular training is carried out in the department and the nurses are competent and confident to initiate resuscitation while awaiting medical help. Some of the registrars are keen to pursue paediatric emergency care as a specialty. It will soon be time to develop postgraduate paediatric emergency training.

There is still a long way to go. Prehospital care is almost non-existent but efforts are underway to improve this; children come in late; drugs, blood or fluids may be unavailable or slow to find. The intensive care unit (ICU) is a four-bedded unit for adults and children, though a new six-bedded paediatric ICU is under construction. All the emergency staff are overworked and more are needed. There needs to be a formal career structure and development plan for nurses, doctors and clinical officers in paediatric emergency care.

\section{CONCLUSION}

The paediatric emergency care unit has a pivotal role in managing sick children arriving to the hospital. The timely management of patients has reduced delays that lead to unnecessary admissions, improved the care and patient flow of sick children, and is an example of good teamwork. Morale is high.

The establishment of a new service in a resource-constrained setting seems daunting but our experience shows that with determination, imagination and foresight it is possible to change practice. Each small advance opened new doors to different types of support and our experience shows the change to be sustainable and self-propagating.

There is still much to be done and learn, and hopefully we will continue to improve and to give an increasingly better service to children and their families.

Acknowledgements The authors thank all the staff of A\&E for their hard work, enthusiasm and care of sick children. The authors also thank the entire paediatric department for their commitment to good emergency care and Mr Servace Sakala for providing much of the data.

Contributors EMM devised the paper and wrote the draft which was reviewed by all the authors. All the authors have looked after children in the emergency department.

Competing interests None declared.

Provenance and peer review Not commissioned; externally peer reviewed.

Open Access This is an Open Access article distributed in accordance with the Creative Commons Attribution Non Commercial (CC BY-NC 4.0) license, which permits others to distribute, remix, adapt, build upon this work non-commercially, and license their derivative works on different terms, provided the original work is properly cited and the use is non-commercial. See: http://creativecommons.org/ licenses/by-nc/4.0/

(c) Article author(s) (or their employer(s) unless otherwise stated in the text of the article) 2017. All rights reserved. No commercial use is permitted unless otherwise expressly granted.

\section{REFERENCES}

1. History of CPR - CPR and ECC - American Heart Association http://cpr.heart.org/AHAECC/CPRAndECC/AboutCPRFirstAid/ HistoryofCPR/UCM_475751_History-of-CPR.jsp 
2. Hallas P, Ekelund U, Bjørnsen LP, et al. Hoping for a domino effect: a new specialty in Sweden is a breath of fresh air for the development of scandinavian emergency medicine. Scand J Trauma Resusc Emerg Med 2013;21:26.

3. Obermeyer Z, Abujaber S, Makar M, et al. Reynolds TA \& on behalf of the acute care development consortium emergency care in 59 low- and middle-income countries: a systematic review. Bulletin of the World Health Organization 2015;93586G:577.

4. WHO | emergency Triage Assessment and treatment (ETAT) course. http://www.who.int/child adolescent health/documents/ 9241546875/en/ (accessed Jun 2016).

5. Phillips BM, Mackway-Jones K, Molyneux E, et al. Advanced paediatric life support. Current Paediatrics 1997;7:48-52.

6. Molyneux EM, Malenga G. Forms of better care. World Health Forum 1997;18:71-9

7. Rogerson S, Malenga G, Molyneux EM. Integrated care pathways: a tool to improve infant monitoring in a neonatal unit. Ann Trop Paediatr 2004;24:171-4.
8. Ellis JC, Ahmad S, Molyneux EM. Introduction of HIV post-exposure prophylaxis for sexually abused children in Malawi. Arch Dis Child 2005;90:1297-9.

9. Molyneux EM, Kennedy N, Dano A, et al. Sexual abuse of children in low-income settings: time for action. Paediatr Int Child Health 2013;33:239-46.

10. Coetzee M, Chimwaza A, North N, et al. Sustainable workforce development: building paediatric nurse training capacity for Africa, in Africa. The Lancet Global Health 2016. accepted.

11. Robertson MA, Molyneux EM. Triage in the developing world-can it be done? Arch Dis Child 2001;85:208-13.

12. Robertson MA, Molyneux EM. Description of cause of serious illness and outcome in patients identified using ETAT guidelines in urban Malawi. Arch Dis Child 2001;85:214-7.

13. Ahmad S, Ellis JC, Kamwendo H, et al. Impact of HIV infection and exposure on survival in critically ill children who attend a paediatric emergency department in a resource-constrained setting. Emerg Med J 2010;27:746-9. 